\title{
Arabia Petraea, uma província romana e suas emissões monetárias
}

\author{
Vagner Carvalheiro Porto *
}

PORTO, V. C. Arabia Petraea, uma província romana e suas emissões monetárias. $R$. Museu Arq. Etn., 32: 167-178, 2019.

Resumo: A Arabia Petraea, ou província Arábia como também é conhecida, teve sua fundação pelos romanos em 106 d.C., mas já se constituíra como um reino cliente do Império Romano desde o ano 63 da era comum. Teve uma importante função estratégica de guardar a retaguarda da Judeia e o flanco sul da Síria. A instabilidade gerada por rivalidades e interesses particulares dos diferentes estados clientes acabou inclinando Roma para a solução de uma provincialização gradual e definitiva da região. Apesar de ser o reino cliente mais estável, a Nabateia foi um hiato na geografia oriental do império. Sua anexação respondeu, portanto, a abordagens estratégicas e territoriais de curto e longo prazo, fundamentalmente a uma racionalização da gestão do Oriente Romano, que abriu uma fase completamente nova na história da região. É nosso objetivo neste artigo apresentar o histórico da conquista romana sobre os nabateus, a constituição geográfica desta província e as questões político-econômicas que envolveram a formação desta província romana à época do Imperador Trajano, assim como demonstrar o potencial de reflexão e apreensão do universo político, social, econômico e religioso que as moedas produzidas nesta região podem nos oferecer.

Palavras-chave: Província Arábia; Arabia Petraea, Reino nabateu; Império Romano; Moedas locais.

\section{Considerações iniciais}

Cnosso propósito neste texto apresentar,
num primeiro momento, os nabateus, povo que vivia no Oriente Próximo bem antes da área se converter em província romana $;^{1} \mathrm{em}$ seguida, pretendemos explanar um pouco sobre a localização geográfica conhecida como Nabateia; depois apresentar de modo sucinto como

(*) Museu de Arqueologia e Etnologia da Universidade de São Paulo. Co-coordenador do Laboratório de Arqueologia Romana Provincial, LARP-MAE/USP < vagnerporto@usp.br> se dava a relação entre nabateus e romanos; busco discutir a conversão do reino da Nabateia em Província Arábia e por fim, expor, partindo das moedas, nuances da intencionalidade romana quanto à criação desta província, o estatuto jurídico-administativo da cidade, o caráter local

(1) Neste capítulo resolvi tratar de um tema muito pouco abordado em nosso país: a província romana Arabia Petraea. Havia tangenciado levemente o tema em minha tese de doutorado (Porto 2007) e resolvi explorá-lo um pouco mais nestas linhas que seguem, de modo a permitir que o público brasileiro trave contato com as questões concernentes a esta importante província do Império Romano. 
Arabia Petraea, uma província romana e suas emissões monetárias R. Museu Arq. Etn., 32: 167-178, 2019.

que sutilmente subsiste na iconografia, dentre outros elementos a serem apontados.

\section{Quem eram os nabateus?}

David Soria Molina (2015:313) em seu trabalho Arabia Petraea, de reino cliente a provincia romana (63 a.C.-106 d.C.) nos informa que os primeiros testemunhos escritos clássicos que temos sobre a existência dos nabateus no espaço, encontram-se hoje em dia, grosso modo, na Jordânia (Fig. 1). Diodoro Sículo narra as campanhas parcialmente frustradas empreendidas por Antígono I Monoftalmo contra os nabateus em 312 a.C. O retrato que Diodoro nos transmite deste agrupamento para o final do século IV a.C. é o de um conjunto de tribos e clãs nômades dedicadas ao pequeno pastoreio e ao comércio nas estepes e desertos da

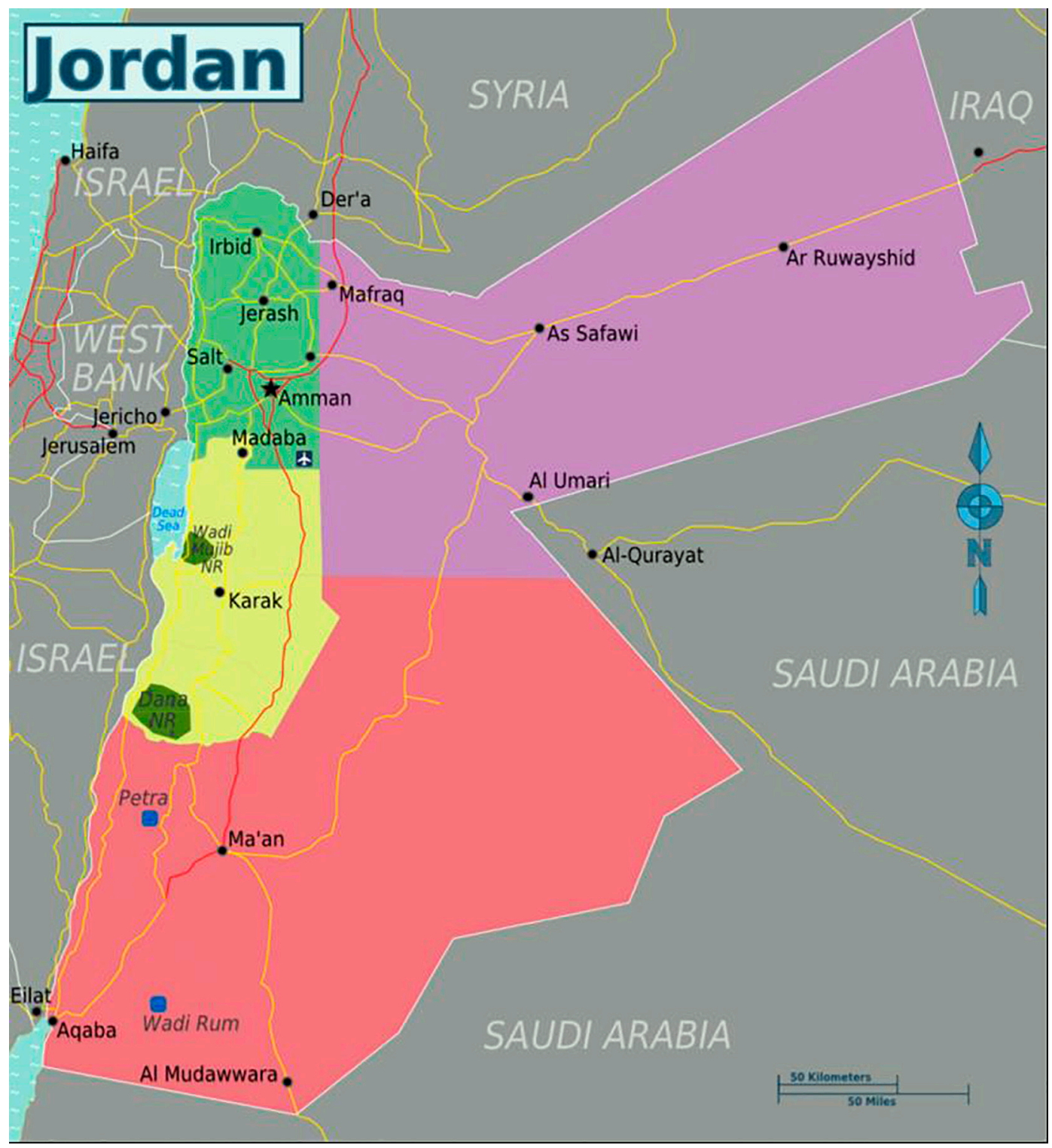

Fig. 1. Mapa da Jordânia. Fonte: Wikipedia.org. https://pt.wikipedia.org/wiki/Portal:Jord\%C3\%A2nia\#/media/ Ficheiro:Map_of_Jordan.pn. Domínio Público. 
Transjordânia, totalmente descentralizados, que se juntavam apenas em contextos de defesa comum e por ocasião de um encontro anual com motivos espirituais e festivos (Soria Molina 2015:313).

As fontes literárias disponíveis não fornecem mais informações relevantes sobre o desenvolvimento histórico dos nabateus até meados do século II a.C. Sabe-se que os nabateus formavam um reino relativamente centralizado em torno da figura de um monarca, com sede administrativa na cidade de Petra (antiga Raqmu), constituindo um Estado famoso por sua estabilidade interna (Molina 2015:313). A essa época, a maioria dos nabateus havia abandonado o pastoreio, dedicando-se a uma rica agricultura graças a extensos trabalhos de irrigação; da mesma forma, os nabateus seguiam dedicando-se ao comércio, possuindo as rotas comerciais que ligavam a Síria, a Palestina, o Egito e o Mar Vermelho. Jane Taylor (2001:124125), pesquisadora dedicada ao estudo dos nabateus, descreve-os como "um dos povos mais talentosos do mundo antigo".

\section{De acordo com Soria Molina (2015:314):}

Obodas I sucedeu a Aretas II no início do século I a.C., mantendo a enérgica política exterior de seu antecessor: derrotou Alexandre Janeu da Judeia nas colinas de Golã por volta de 83 a.C., e pouco depois enfrentou com sucesso as forças de invasão dos reis selêucidas Antíoco XII e Antíoco XIII, derrotando-os esmagadoramente entre 88 e 85 a.C. (Também Taylor 2001).

Aretas III ascendeu ao trono nabateu pouco depois e, após expulsar os itureus das proximidades da cidade de Damasco, assumiu o controle desta cidade entre os anos de 84 e72 a.C., emitindo moedas a partir daí. Segundo Soria Molina (2015:315), o reino dos nabateus alcançou então sua máxima extensão, abarcando toda a Transjordania, a maior parte do Sinai e toda a região de Hawran no sul da Síria (Fig. 2). No entanto, a hegemonia dos nabateus na Síria não duraria muito: em 72 a.C., as forças do rei armênio Tigranes II, o Grande, demoveu dos nabateus o controle de Damasco e seus arredores.
Embora três anos depois os armênios tenham evacuado suas tropas da cidade, Aretas III não tentou recuperá-la. Provavelmente a guerra civil que eclodiu no reino da Judeia em 67 a.C. condicionou fortemente a decisão final do rei nabateu, que contemplou a oportunidade de extrair benefícios notáveis com sua intervenção em favor de um dos dois lados. Este movimento acabaria arrastando a Nabateia para um conflito direto com Roma e consequentemente, fazendo com que esta alcançasse o status de estado cliente do Estado Romano (Soria Molina 2015:314-315).

Josefo, tanto nas Antiguidades Judaicas (Ant. XII-XIV) quanto na Guerra dos Judeus contra os romanos (War II), afirma que no ano 65 a.C. as legiões romanas comandadas pelos legados de Pompeu entraram em Damasco, apropriando-se do coração da Síria.

Emilio Escauro, legado do procônsul, avaliou a situação na Judeia e Nabateia e finalmente escolheu alinhar Aristóbulo a Roma, pretendente ao trono da Judeia e rival de Hircano, outro pretendente apoiado por Aretas III (Retsö 2003:365). Escauro pediu formalmente aos nabateus que retirassem seu apoio a Hircano sob a ameaça de um ataque romano. Aretas III concordou, sendo logo depois atacado e derrotado pelas forças de Aristóbulo (Soria Molina 2015:315). Enquanto isso, em 64/63 a.C., Pompeu chegou à Síria, convertendo-a oficialmente em uma nova província romana. Muitas moedas da cidade a partir daí passaram a ter a inscrição "Gadara Pompeiana" (Porto 2007:182). Ele reconstruiu a cidade de Gadara e restaurou sete cidades do interior e quatro costeiras. Pompeu fez de Jerusalém um afluente de Roma e fez da Judeia um satélite da Síria. De acordo com Flavio Josefo, Pompeu, em seguida, foi para a Cilícia, levando Aristóbulo e seus filhos com ele, e depois retornou a Roma (Josephus, Ant., XV, 54-79). Isso contrasta com o relato de Plutarco. Este último não mencionou nenhuma ação na Judeia. Plutarco escreveu que Pompeu teria marchado em direção a Petra (capital do Reino nabateu) para confirmar Aretas, que queria se tornar amigo de Roma. De acordo com este relato, Pompeu teria sido avisado da morte de Mitrídrates em um acampamento próximo a Petra. 
Arabia Petraea, uma província romana e suas emissões monetárias R. Museu Arq. Etn., 32: 167-178, 2019.

Pompeu então teria deixado a Arábia e ido para Amisus (Samsun), no Ponto, costa norte da Anatólia (Plutarco, Parallel Lives, The Life of Pompey). Josefo escreveu que Pompeu marchou para a Nabateia, mas não mencionou a razão para isso. Teria também marchado para a Judeia para lidar com Aristóbulo. Ele não mencionou se chegara a Petra antes de se voltar para a Judeia. $\mathrm{Na}$ versão de Josefo, teria sabido ele da morte de Mitrídates quando marchava em direção a Jerusalém. Quando completou suas questões na Judeia, teria ido Pompeu para a Cilícia, ao invés

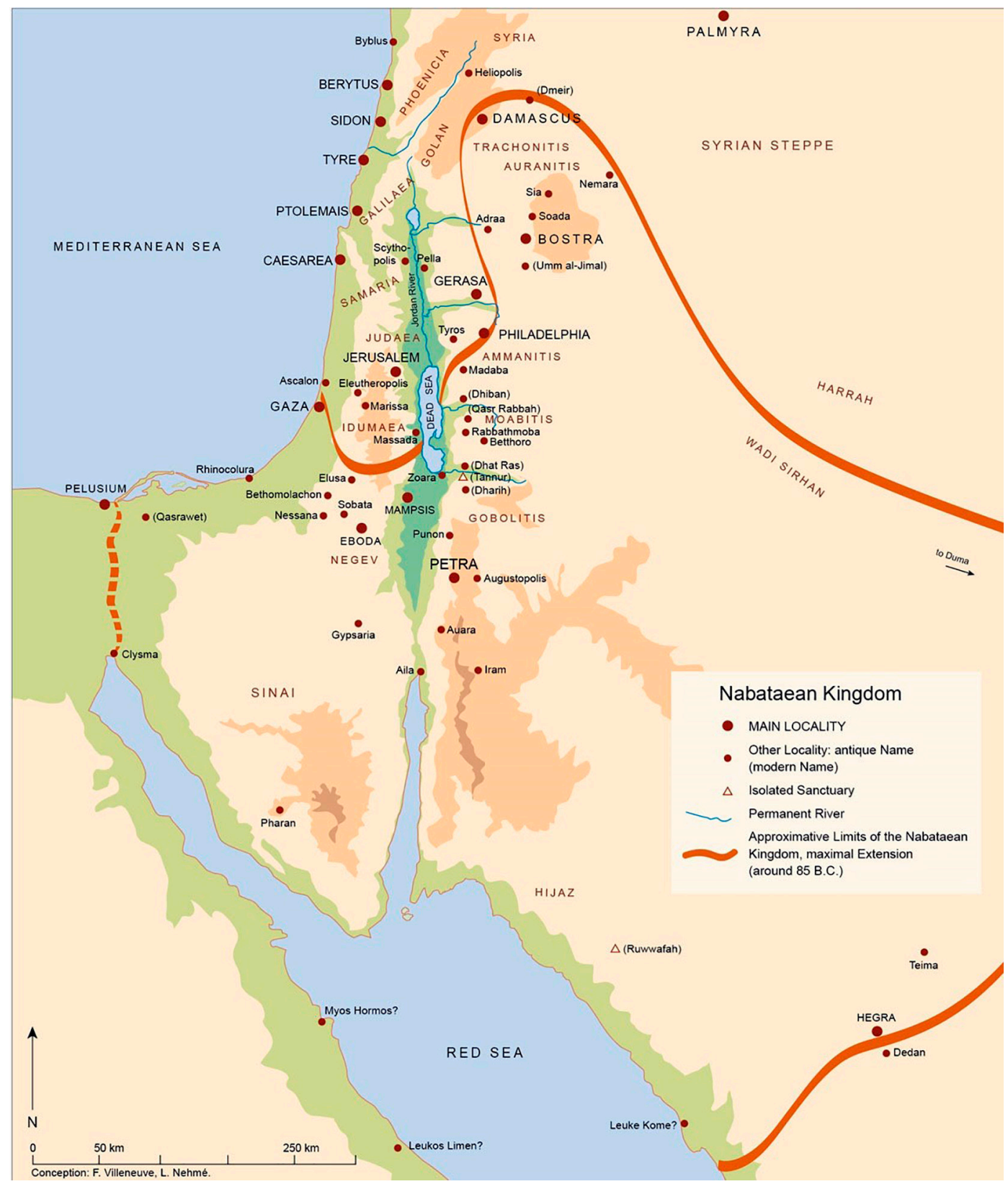

Fig. 2. Principais localidades e máxima expansão do reino dos nabateus, de 85 a 72 a.C.

Fonte: https://commons.wikimedia.org/wiki/File:Nabatean_Kingdom_map.jpg Domínio Público. 
de Amisus. Cassius Dio fez um breve relato da campanha de Pompeu na Judeia e escreveu que depois desses eventos ele teria ido para o Ponto, o que se encaixa com a versão de Plutarco de que ele teria ido para Amisus (Cassius Dio, Roman History, 37.14.3, 15-17, 20.1)

Em 62 a.C. o procônsul teve que retornar a Roma, deixando Emilio Escauro encarregado de resolver a querela entre os líderes locais, atuando politicamente no alinhamento de Aristóbulo a Roma, e opondo-se a Hircano e consequentemente a Aretas III, como vimos linhas acima. De acordo com Soria Molina (2015:316), o legado, sem uma aparente razão concreta, abriu hostilidades contra Aretas III, liderando uma expedição contra seus domínios. A guerra não se concretizou: o rei nabateu chegou a um acordo de paz pagando 300 talentos de ouro; as forças romanas se retiraram depois de assegurar a lealdade e a disposição dos nabateus como seus novos vassalos (Soria Molina 2015:316-317).

Josefo nos informa que desde 47 a.C., o reino dos nabateus combateu ao lado das filas de Julio César contra Pompeu.

Logo na sequência Obodas II torna-se um fantoche nas mãos de seu ministro-chefe, Sileus, que se tornaria o verdadeiro governante da Nabateia durante a maior parte do reinado de Otávio Augusto, em Roma. A rara moeda abaixo (Fig. 3) faz parte da série de moedas batidas conjuntamente por Sileus e Aretas IV.

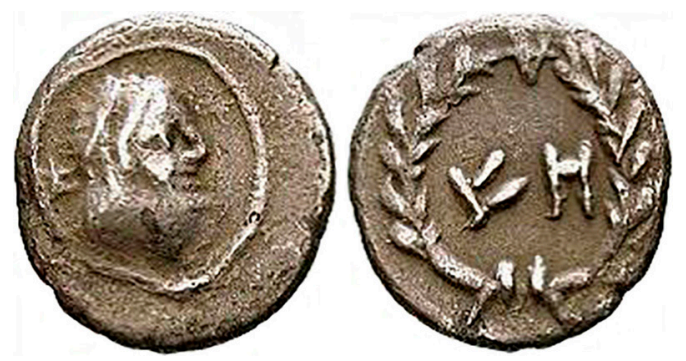

Fig. 3. Dracma de prata emitidido por Sileus e Aretas IV. Anv: busto diademado de Obodas II. Legendas de anverso: Monograma em aramaico "Shin", (Sileus). Rev: dentro de coroa de louros. Legendas de reverso: em nabateu, "Shin" (Sileus) e "het" (Aretas). Fonte: Y. Meshorer Nabataean Coins 4; V. C. Porto. Imagens monetárias na Judeia/Palestina sob dominação romana. Tomo II, 2007: 373.
Em 24 a.C. Sileus traiu Roma causando grande destruição a um exército romano enviado para a Arábia Felix (Porto 2007: 197). Sileus foi duas vezes chamado para a Corte de Roma, onde em 6 a.C. foi condenado por traição e pela morte de Obodas. Foi decapitado e seu corpo lançado da Rocha Tarpeia (Estrabão Geografia, XVI, 22-24).

A instabilidade política na região voltou a crescer com a morte de Herodes, o Grande, em 4 a.C., quando seu reino foi dividido entre seus sucessores. Estrabão nos lembra que, forçado a escolher entre uma multiplicidade de pequenos estados judeus e Aretas IV, Augusto viu-se inclinado a se livrar do rei Nabateu: a Nabateia foi anexada, assim, pela primeira vez como província, ficando sob a responsabilidade de um procurador imperial (Soria Molina 2015:317318).

Na sequência Aretas IV, com respaldo romano, iniciou a segunda parte de seu reinado, considerado como o principal apogeu do reino dos nabateus (Tabela 1).

\section{De Nabateia à província Arabia (Arabia Pe- traea)}

Segundo G. W. Bowersock (1971:221), Aretas IV, Filopátris, situou sua corte e o núcleo administrativo do reino definitivamente em Petra (cidade que alcançou seu máximo desenvolvimento nesta época), elaborou uma ideologia de poder definida através do que poderíamos considerar quase como um culto dinástico a seus predecesores no trono e impulsionou o desenvolvimento agrícola e urbano dentro de seus domínios. Importante frisar que a maior parte desta informação é conhecida graças à epigrafia e a arqueologia. As fontes literárias clássicas permanecem mudas em torno da sorte dos nabateus até o começo da década de 30 d.C.

David Soria Molina (2015:323) nos informa que em 22 de março de 106 d.C. o governador da Síria, Cornélio Palma, seguindo ordens imperiais, proclamou a anexação do reino dos nabateus ao estado romano na forma da nova província Arábia, desta vez de modo definitivo e irreversivel. 
Arabia Petraea, uma província romana e suas emissões monetárias

R. Museu Arq. Etn., 32: 167-178, 2019.

\begin{tabular}{|c|c|c|}
\hline Reign & Name & Notes \\
\hline \multicolumn{3}{|l|}{ Kings of Nabataea } \\
\hline c. $169 \mathrm{BC}$ & Aretas 1 & \\
\hline $120 / 110$ to $96 \mathrm{BC}$ & Aretas II & In some sources appears as successor to Rabbel I \\
\hline c. 96 to $85 \mathrm{BC}$ & Obodas I & \\
\hline c. $85 / 84 \mathrm{BC}$ & Rabbel I & In some sources appears as successor to Aretas II \\
\hline 84 to $60 / 59 \mathrm{BC}$ & Aretas III Philhellen & Recognised by Rome $62 \mathrm{BC}$ \\
\hline 30 to $9 \mathrm{BC}$ & Obodas III & \\
\hline \multirow[t]{3}{*}{$9 / 8 \mathrm{BC}$ to $39 / 40$} & Aretas IV Philopatris & \\
\hline & Huldo, Queen & \\
\hline & Šagilat, Queen & \\
\hline $39 / 40$ to $69 / 70$ & Malichus II & \\
\hline
\end{tabular}

Tabela 1. Reis nabateus. Fonte: https://en.wikipedia.org/wiki/List_of_Nabataean_kings. Domínio Público.

A anexação da Arábia não foi um movimento improvisado por parte do poder romano. Se tratou de um passo a mais no amplo programa expansionista elaborado pelo imperador Trajano e seu governo. Rabel II, Soter, era bastante idoso quando o imperador Trajano iniciou seu reinado. Rabel II (ar-Rabil) era o último governante do Reino nabateu, de 70 a 106 d.C. (Taylor 2001:73-74 e Schürer et al. 2015:583).

Segundo Soria Molina (2015:323), o poder romano considerou mais oportuno aguardar o falecimento do soberano para proceder a anexação ao invés de depor o rei ancião. E assim aconteceu: pouco depois da morte de Rabel II, Cornélio Palma marchou a partir da Síria com a legião VI Ferrata, enquanto a III Cyrenaica marchou a partir do Egito através da Palestina, reunindo-se aos prováveis contingentes auxiliares que os seguiram nas principais cidades da Nabateia: Petra e Bostra (Soria Molina 2015:323-324; Chancey e Porter: 185). As cunhagens comemorativas da anexação trazem a legenda $\operatorname{arab}(i a)$ adquis(ita) e não cap(ta), sublinhando o carácter aparentemente pacífico da anexação.

A consolidação dos limites e domínios romanos na região, além das pretendidas campanhas sobre a Armênia e o império parta se encontrava entre as principais motivações da anexação da Arábia. Muito importante dizer que a aquisição da Arábia culminou no processo de provincialização do Oriente romano, particularmente o entorno da província Síria e Palestina (Sartre 1991:46).

\section{Nasce a província Arábia}

Em 22 de março de 106 d.C. a nova província Arábia nasceu oficialmente, ocupando grosso modo o mesmo espaço do reino dos nabateus que a precedeu.

Paolo Cimadomo, no artigo intitulado The controversial annexation of the Nabataean King. dom, publicado em 2018, apresenta um debate contrariando a ideia de que a criação da província romana Arábia em 106 d.C. tenha sido considerada substancialmente pacífica, de natureza administrativa e com escasso uso de força militar (ele cita diversos autores que vão nesta linha como Bowersock 1983:82-85; Fiema et al. 2015:375; Isaac 1990:119; Raschke 1978:647-48 e Strobel 1988). Sugere, no entanto, que várias informações nos levam a supor que a anexação do antigo reino nabateu não se deu, de fato, totalmente sem sangue (Cimadomo 2019:258).

Soria Molina (2015:326-327), por sua vez, indica que as forças da III Cyrenaica se encarregaram da construção da maior parte das infraestruturas da nova província durante o período que se extendeu entre sua anexação e a eclosão das guerras de Trajano com os partas. A via Nova Traiana, que tem sua construção através de seus marcos miliários em 111 d.C., constitui possivelmente o melhor testemunho material da gestão romana da província Arábia sob Trajano. Incorporando a seu traçado a antiga calçada real construída pelos reis nabateus, a nova via atravessou a Arábia em direção norte-sul iniciando na Síria, atravesando Bostra e Petra até alcançar os portos do golfo de Aqaba. Nestas mesmas 
datas o Império Romano começou a emitir as primeiras cunhagens proclamando a nova província (Cimadomo 2019:262).

Soria Molina (2015:327) afirma que do ponto de vista sociopolítico e urbano, a cidade de Bostra foi elevada ao estatuto de municipium. Petra, apesar de ter deixado de ser a capital, foi objeto de adições arquitetônicas, como uma via porticada e um arco triunfal erigido em 114 d.C. A cidade recebeu de Trajano o título de metropolis Arabia, conservando uma constituição própria de uma cidade helênica com aditamentos legais latinos que a equipararam em status a um municipium romano. Por volta de 124 d.C. recebeu o status de colonia romana.

Depois de ter se constituído em um reino cliente do Império Romano desde 63 d.C., protegendo a retaguarda da Judeia e do flanco sul da Síria, a Arábia cumpriria exatamente esta mesma função como uma província romana até ser dominada pela conquista muçulmana em 636 d.C.

\section{As emissões monetárias das cidades da Arabia Petraea}

A agora chamada Província Arábia passou a incluir as cidades de Gerasa, Filadélfia, Canata e Dium que anteriormente faziam parte da divisão político-administrativa da Decápolis (Cruz 2018:28). Segundo Spijkerman (1978:17), as cidades de Moabitide, Esbous, Medaba, Rabbathmoba, Charachmoba, Petra e Bostra - afirmadas por benesses públicas - também se destacam em seu contexto com o controle militar da região e com a reativação das rotas do comércio de caravanas (Spijkerman 1978:17). Essa reorganização foi tão bem-sucedida que a seguinte ocorreria apenas em torno de 295 d.C. com a reforma de Diocleciano, que criaria novas unidades políticas como a Palaestina Secunda e a Palaestina Tertia ou Salutaris (Spijkerman 1978:17-19; Cruz 2018:28-29).

As cidades que produziram moedas na província Arabia foram: Adraa, Bostra, Canata, Capitolias, Charach-Moba, Eboda, Dium, Esbous, Gadara, Gerasa, Hippum, Medaba, Nysa-Scythopolis, Pella, Petra, Philadelphia, Philippopolis e Rabbath Moba. Destacarei atenção, nas linhas que me restam, a duas dessas cidades produtoras, por sua importância política local e pela diversidade de suas emissões.

Dessas, Petra (cujo nome hebraico-aramaico é Reqem) é a primeira a qual pretendo explanar na sequência. Já abordamos algumas passagens da história e geografia dos nabateus em que esta importante cidade foi mencionada. Como vimos, ela foi capital do reino nabateu até 106 d.C. quando Trajano anexou-a à nova província Arábia. O início da produção monetária desta cidade remonta a 100 a.C., momento em que esta era a maior produtora de moedas da Nabateia. O gráfico a seguir evidencia a deusa protetora da cidade, Tyche, em suas emissões monetárias (Gráfico 1). Esta foi a divindade mais representada em suas moedas, assim como o Imperador Adriano foi seu governante mais retratado.

As moedas batidas em Petra durante o período de dominação romana seguiram o estilo nabateu. É o caso da imagem a seguir (Fig. 4a) emitida sob Trajano que traz a deusa Tyche em total estilo nabateu. Essa moeda apresenta duas cornucópias cruzadas no reverso e, acima, um monograma $\mathrm{M}$, que corresponde às letras iniciais da inscrição: P[ETPA] M[ETPOPOLIS (Porto 2007:197). A cunhagem local, de uma moeda em estilo nabateu, apresenta-nos reflexões sobre hibridismo e emulação envolvendo Roma e a província Arábia, não apenas do aporte artístico nabateu empregado em moedas - agora - romanas, mas diz respeito também às estratégias de entendimento entre romanos e povos locais nos mais variados âmbitos: não podemos deixar de lembrar que as esferas todas das sociedades antigas eram imbricadas e, com isso, há muito mais que se pensar, quando acontece algo em uma das esferas da vida da cidade.

O tipo mais importante sobre as moedas de Petra é a representação de Tyche, a deusa principal da cidade (que é identificada com Allat, a deusa nabateia da fertilidade). Na próxima imagem (Fig. 4b), a deusa está sentada em uma rocha, talvez simbolizando o penhasco em que a cidade está situada (Porto 2007:197).

Tyche segura um troféu em uma clara alusão à vitória e estabelecimento de um controle romano na região. Por último, em relação às moedas de Petra, destaco uma moeda com 


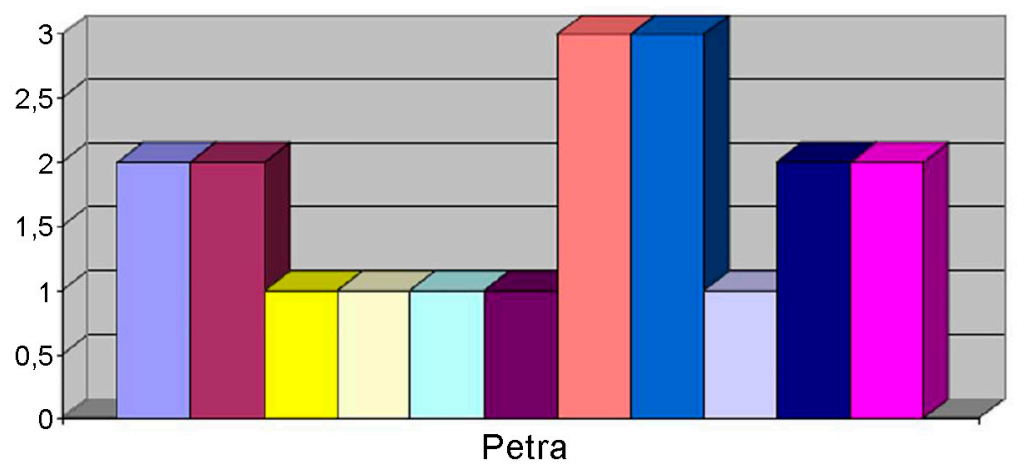

$\square$ Obodas II
$\square$ Aretas IV
$\square$ Syllaeus
$\square$ Rainha Shuquailat
$\square$ Rabbel II
$\square$ Rainha Gamalat
$\square$ Adriano
$\square$ Tyche
$\square$ Águia
$\square$ Cornucópias cruzadas
$\square$ Coroa de louros

Gráfico 1. Tipos monetários principais nas moedas de Petra. Fonte: Porto. Imagens monetárias na Judeia/Palestina sob dominação romana. Tomo II, 2007: 196.

a inscrição METROPOLIS. Esta moeda foi produzida em Petra à época do Imperador Adriano. Traz em seu anverso o busto laureado e couraçado de Adriano com barba à direita. A legenda de anverso, em grego, é: AVTOKPATWP KAICAP TPAIANOC A $\triangle$ PIANOC CEBACTOC. O reverso apresenta uma coroa de louros. A Legenda de reverso, também em grego diz: PETPA MHTPOPOLIC, que significa: Petra Metropolis. (Porto 2007:377). Petra cessou suas emissões monetárias em 222 d.C.

A outra cidade em que nos deteremos agora em apresentar os tipos monetários, e que não poderia ficar de fora do escopo de nossas observações, é Bostra (também conhecida como Bosra e Beser). Como mencionado anteriormente, junto com Petra, esta cidade está entre as mais importantes da região,
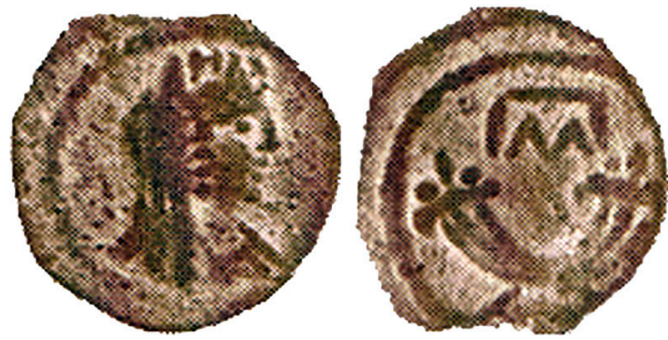

Fig. 4a. Moeda batida em Petra depois de 106 d.C., ano da fundação da província Arabia. Anv.: busto de Tyche velado com coroa de torres, em estilo nabateu. Ver: duas cornucópias cruzadas. Legendas de reverso: em grego, monogramas PM = PETRA MHTROPOLIC, significando as iniciais das letras de Petra e de Metropolis em grego. Fonte: Porto. Imagens monetárias na Judeia/ Palestina sob dominação romana. Tomo II, 2007: 375. antes sendo capital do reino nabateu, agora, como Arabia Petraea mantém sua importância política e econômica. Bostra está situada a leste da Transjordânia, em um local chamado na atualidade Basra. Com a incorporação do reino nabateu e sua transformação em província da Arábia por Trajano em 106 d.C., a cidade tornou-se a capital da província. De acordo com Alla Stein, o primeiro título que a cidade recebeu foi "a nova Bostra Trajana".

Os dois gráficos a seguir (Gráficos 2 e 3) mostram os principais tipos iconográficos presentes nas moedas batidas nesta cidade sob dominação romana.

Diversos tipos iconográficos são representados sobre as moedas dessa cidade, incluindo

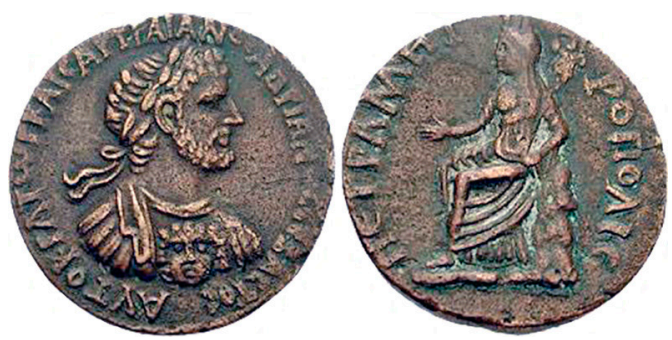

Fig. 4b. Moeda batida em Petra à época do Imperador Adriano. Anv.: busto laureado e couraçado de Adriano com barba (górgona em seu peito). Legendas de anverso: em grego, AVTOKPATWP KAICAP TPAIANOC A $\triangle$ PIANOC CEBACTOC. Rev.: Tyche velada e com coroa de torres, sentada à esquerda sobre rocha, vestindo quíton longo. Sua mão direita está estendida. Troféu em sua mão esquerda. Legendas de reverso: em grego, PETPA MHTPOPOLIC (Petra Metropolis). Fonte: Porto 2007: 376. 
o camelo, que sempre simbolizou a região porque esse local sempre foi passagem das caravanas. $\mathrm{O}$ camelo aparece representado sozinho na moeda (Fig. 5a) e ao lado da representação da Arábia na moeda (Fig. 5b). O meio torso de Arábia é representado "flutuando" na moeda emitida por Adriano (Fig. 5c). Segundo Yakov Meshorer, o camelo é também representado sobre as moedas produzidas por Trajano em Roma para marcar o estabelecimento da província da Arábia, e por Roma ter submetido o reino nabateu em um contexto similar. Nas moedas republicanas romanas de Escauro, depois de 61 a.C., Aretas III, rei dos nabateus, é apresentado ajoelhado em submissão, e o camelo está ao seu lado, representando a região.

A próxima moeda (Fig. 6a) possui um esquema iconográfico bastante interessante. Ela apresenta três estandartes (vexilla) com a águia legionária, no topo do estandarte do centro, uma coroa, no topo do estandarte da esquerda, e uma mão, no topo do estandarte da direita. Essa legião estacionou em Bostra e deixou sua marca sobre o culto praticado na cidade, assim como nas moedas de Bostra.

Finalmente, a moeda seguinte (Fig. 6b) apresenta o tipo singular de Ártemis de Perge. Este tipo foi, durante a primeira metade do século XX, atribuído a Cesaréia, na Capadócia, mas estudos posteriores mostraram que essa moeda foi produzida em Bostra. O culto de Ártemis de Perge foi bastante difundido pelos reis helenísticos e com a dominação romana o culto se manteve bastante intenso em todas as províncias do Leste (Porto 2007:178).

Sob Alexandre Severo, Bostra foi elevada à condição de Colônia e sob Felipe, o Árabe, (244-249 d.C.) a cidade conquistou o título de Metropolis. As emissões de Bostra cessaram com Herênio Etrusco e Hostiliano no ano de 251 d.C. (Porto 2007:176).

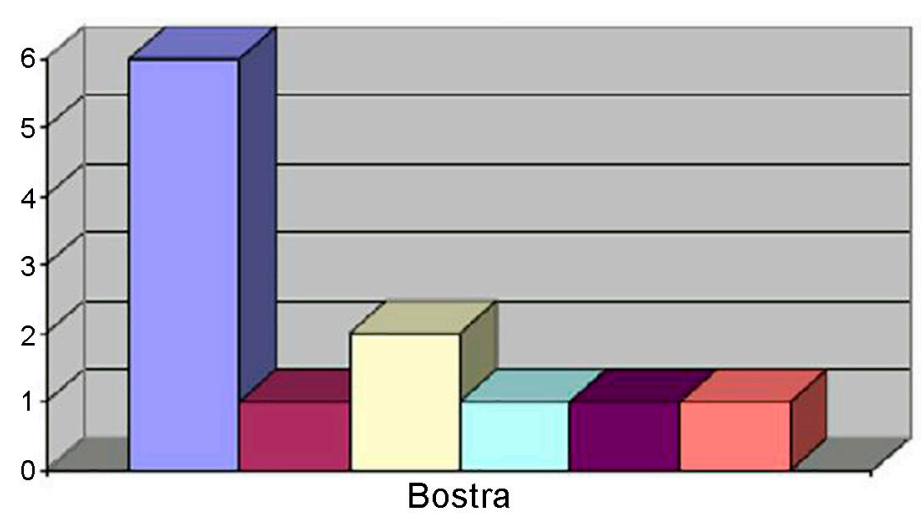

Gráfico 2. Tipos principais nas moedas de Bostra.

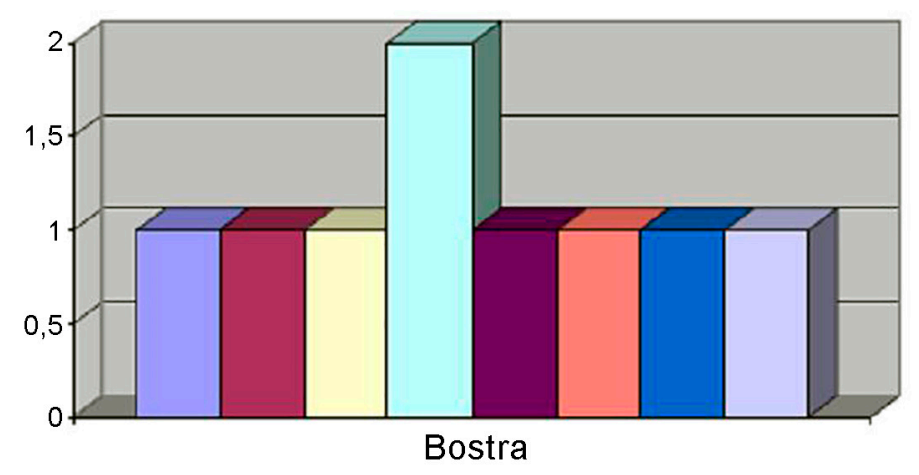

Gráfico 3. Tipos secundários nas moedas de Bostra.

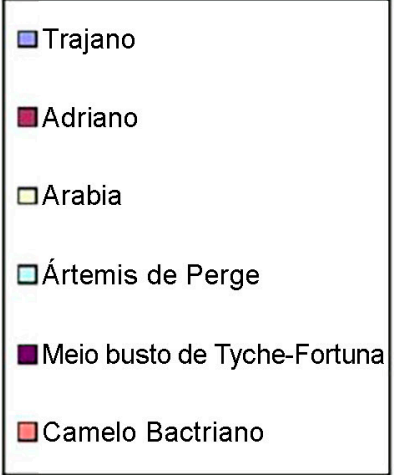

$\square$ Feixe de canela

$\square$ Camelo

$\square$ Templo distilo

$\square$ Águia

Geixe de espigas de trigo

$\square$ Três estandartes

$\square$ Coroa de louros

口Uma mão 

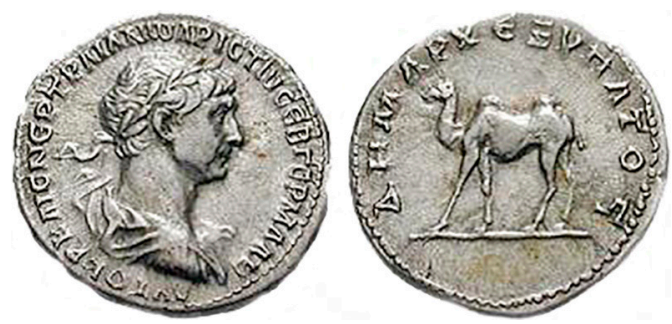

Fig. 5a. Moeda batida em Bostra à época do Imperador Trajano. Anv.: busto laureado e drapejado de Trajano; borda de pontos. Legendas de anverso: em grego, AVTOKP KAIC NEP TPAIANW APICTW CEB ГEPM $\triangle \mathrm{AK}$. Rev.: camelo bactriano avançando, à esquerda. Legendas de reverso: em grego, $\triangle$ HMAPX Е $\Xi$ YПАТО s. (Petra Metropolis). Fonte: Porto 2007: 293.
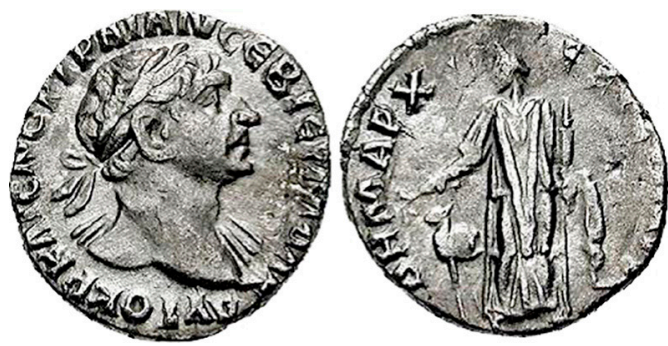

Fig. 5b. Moeda batida em Bostra à época de Trajano. Anv.: busto laureado de Trajano. Legendas de anverso: em grego, AVTOKPATWP KAICAP NEP. TPAIANOC A $\triangle$ PIANOC CEBACTOC ГEPM $\triangle A K$. Rev.: Arábia em pé, em posição frontal; abaixo, parte dianteira de um camelo. Legendas de reverso: em

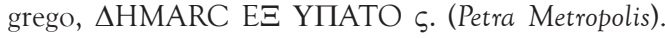
Fonte: Porto 2007: 293.

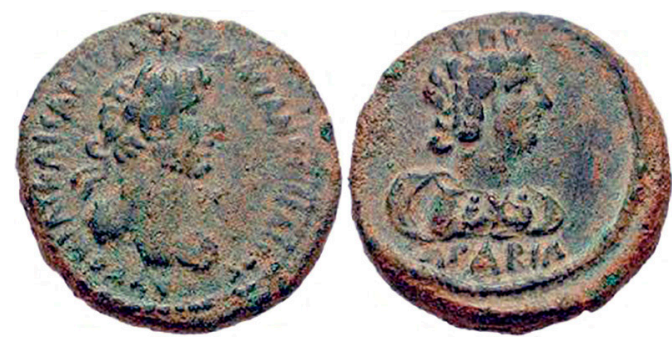

Fig. 5c. Moeda batida em Bostra à época do imperador Adriano. Anv.: busto laureado de Adriano virado à direita. Bordas de pontos. Legendas de anverso: em grego, AVTOKPATWP KAICAP TPAIANOC A $\triangle$ PIANOC CEBACTOC. Rev.: busto de Arábia com coroa de torres, à direita, embalando nos braços duas crianças. Legendas de reverso: em grego, APABIA. Fonte: Porto 2007: 299.

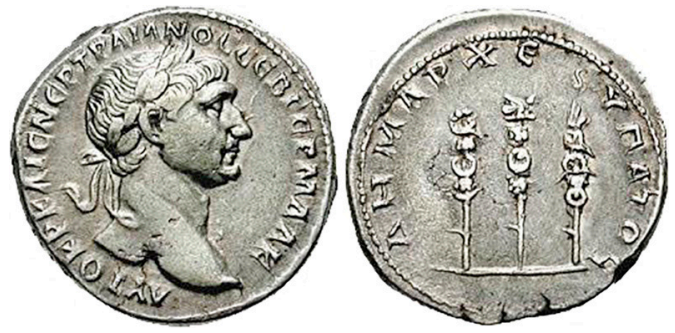

Fig. 6a. Moeda batida em Bostra à época de Trajano. Anv.: busto laureado e drapejado de Trajano com aegis, virado para a direita. Legendas de anverso: em grego, AVTOKPATWP KAICAP NEP. TPAIANOC A $\triangle$ PIANOC CEBACTOC GERMA. Rev.: três estandartes (vexilla). Águia legionária, no topo do estandarte do centro. Coroa, no topo do estandarte da esquerda. Uma mão, no topo do estandarte da direita. Legendas de reverso: em grego,

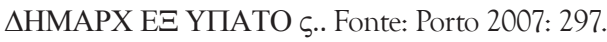

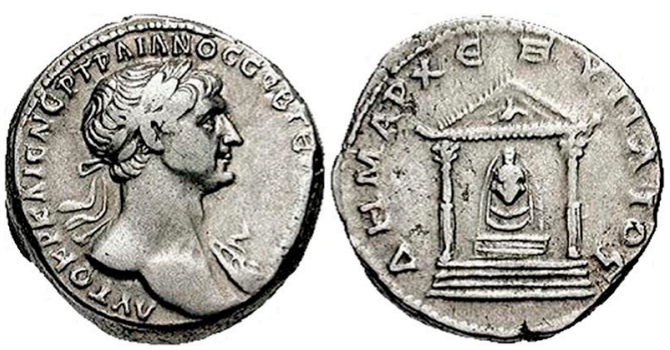

Fig. 6b. Moeda batida em Bostra à época de Trajano. Anv.: busto laureado e drapejado de Trajano usando aegis, virado para a direita. Legendas de anverso: em grego, AVTOKPATWP KAICAP NEP. TPAIANOC ADPIANOC CEBACTOC GERM DAK. Rev.: Templo distilo sobre podium de quatro degraus; águia no pedimento. Dentro, estátua de Ártemis de Perge. Legendas de reverso: em grego, DHMARC EX UPATO V. Fonte: Porto 2007: 295. 


\section{Considerações finais}

Muitas foram as sucessões dinásticas que ocorreram na região desde o domínio nabateu até o romano, como pudemos ver nas linhas deste trabalho.

A pujança e riqueza tanto material quanto cultural dos nabateus foram absorvidas pelos romanos em meio às tempestades políticas e militares nesta pequena faixa territorial do Oriente Próximo.

A Nabateia tinha uma importância estratégica e econômica para Roma porque controlava as rotas de comércio que traziam a mirra e outros artigos luxuosos do Iêmen e da Índia, além de proteger as fronteiras do império. Consequentemente, seus reis experimentaram algum grau de autonomia e adquiriram muita riqueza e bastante influência junto a outras cidades da região.

A anexação do território nabateu por Roma trouxe a criação da província Arábia, conhecida pelas fontes latinas como Arabia Petraea. O imperador Trajano ordenou que se fortificassem as fronteiras e, por volta de 114 d.C., completou a via Nova Trajana, ligando Bostra a Ácaba. Desse modo, assegurou que as rotas de comércio fossem mantidas abertas e os produtos da Arábia continuassem a transitar por Roma (Millar 2001:400-408). As legiões estacionadas na região principalmente a VI Ferrata e a III Cyrenaica foram cruciais para toda essa movimentação política e construtiva. As moedas que trouxemos mostram muito claramente a importância do exército romano nestas paragens.
A marcada presença do camelo e da própria Arábia nas moedas de Bostra e Petra aqui tratadas - lembremo-nos que estes e tantos outros símbolos eram retratados nas moedas das demais cidades produtoras da província Arábia - nos indicam como a herança cultural nabateia perpassou o tempo e se manteve viva mesmo em época romana. Também importante destacar a representação de divindades como é o caso de Tyche, fartamente retratada nas moedas, dentre tantas outras.

Não devemos nos esquecer que a linha que separa a estratégia político-ideológica dos romanos e a resistência, se assim podemos dizer, das populações locais é bastante tênue. Por um lado, demonstra um entrosamento de Roma com o povo local principalmente exibidos pelas representações nos reversos das moedas localmente produzidas. Por outro, enfatiza o Império Romano ao destacar as efígies, os títulos dos imperadores e seus atributos nos anversos dessas mesmas moedas.

A leitura iconográfica das moedas despertou-nos para questões importantes como a "romanização" preconizada por alguns estudiosos desatualizados, a busca por entender o elemento local, o respeito à análise do contexto, a importância da discussão sobre identidades e tantas outras que nos levam a abandonar a velha dicotomia no entendimento das relações entre romano e não-romano como "conquistador" e "conquistado" e assumir que as relações entre Roma e Arabia Petraea devam ser vistas e analisadas como interações recíprocas, de múltiplas mãos.

PORTO, V. C. Arabia Petraea, a Roman province and its monetary issues. R. Museu Arq. Etn., 32: 167-178, 2019.

Abstract: Arabia Petraea, or Rome's Arabian Province as it is also known, was founded by the Romans in $106 \mathrm{AD}$, but had been a client kingdom of the Roman Empire since the year 63 of the Common Era. It had an important strategic role in guarding the rear of Judea and the Southern flank of Syria. The instability generated by the rivalries and particular interests of the different client states eventually inclined Rome towards the solution of a gradual and definitive provincialization of the region. Despite being the most stable client kingdom, Nabataea was a hiatus in the Eastern geography of the empire. Its annexation thus responded to short and long-term strategic and territorial approaches, fundamen- 
Arabia Petraea, uma província romana e suas emissões monetárias

R. Museu Arq. Etn., 32: 167-178, 2019.

tally to a rationalization of the management of the Roman East, which opened a completely new phase in the history of the region. It is our aim in this paper to present the history of the Roman conquest of the Nabataeans, the geographical constitution of this province, and the political and economic issues surrounding the formation of this Roman province at the time of Emperor Trajan. It is our intention to demonstrate the potential for reflection and apprehension of the political, social, economic and religious universe that the coins produced in this region can offer us.

Keywords: Rome's Arabian Province: Arabia Petraea; Nabataean Kingdom; Roman Empire; Local currencies.

\section{Referências bibliográficas}

Bowersock, G. W. 1971. A Report on Arabia Provincia. The Journal of Roman Studies, 61: 219-242.

Chancey, M. A., Porter, A. L. 2001. The Archaeology of Roman Palestine. Near Eastern Archaeology, vol. $64, n^{\circ}$ 4: 164-203.

Cruz, M. M. 2018. Um estudo numismático: levantamento e análise dos esquemas iconográficos militares de moedas da Palestina romana entre os séculos I e III EC. Relatório Final Iniciação Científica. Orientador: Porto, V. C. São Paulo, Fapesp, 2018.

Dio Cassius. 2005. Roman History. Trad. Earnest Cary. (LOEB, v. 176). Harvard University Press, London.

Josephus, F. 1998. Jewish antiquities. Translation Ralph Marcus. Harvard University Press, London.

Josephus, F. 2001. Life of Josephus. Translation Steve Mason. Brill, Leiden.

Millar, F. 2001. The Roman Near East 31 BC - AD 337. Harvard University Press, Cambridge, Mass.

Plutarch. 1917. The Parallel Lives. Vol. V. Loeb Classical Library edition, London.

Porto, V. C. 2007. Imagens Monetárias na Judeia/Palestina sob dominação romana. Tese de Doutorado. Tomos I e II. Museu de Arqueologia e Etnologia da Universidade de São Paulo. São Paulo.
Retsö, J. 2003. The Nabatean problem. The Arabs in Antiquity: Their History from the Assyrians to the Umayyads. Routledge Curzon, London \& New York: 364-391.

Sartre, M. 1991. L'Orient romain. Provinces et sociétés provinciales en Méditerranée orientale d'Auguste aux Sévères (31 av. J.-C. - 235 ap. J.-C), (L’Univers historique). Seuil, Paris.

Schürer, E. 1986. The History of the Jewish People in the Age of Jesus Christ (175 B.C.-A.D. 135). A new English version rev. and ed. Geza Vermes, Fergus Millar and Martin Goodman III, 1. T. and T. Clark, Edinburgh.

SNG ANS. 1981. Syllogue Nummorum Graecorum. The Collection of the American Numismatic Society, Parte 6: Palestine - South Arabia. Nova Iorque.

Soria Molina, D. 2015. Arabia Petraea, de reino cliente a província romana (63 a. C.-106 d. C.). In: Bravo, G.; González Salinero, R. (Eds.) Poder central y poder local. Dos realidades paralelas en la órbita politica Romana. Signifer Libros, Madrid, Salamanca: 313-330.

Spijkerman, A. 1978. The Coins of the Decapolis and Provincia Arabia. Piccirillo, M. (Ed.) Studii Biblici Franciscani collectio maior, XXV). Franciscan Printing, Jerusalem

Taylor, J. 2001. Petra and the Lost Kingdom of the Nabataeans. B. Tauris, London. 